\title{
AN INVESTIGATION ON SWITCHING BEHAVIOURS OF VECTOR CONTROLLED INDUCTION MOTORS
}

\author{
Y1lmaz Korkmaz ${ }^{1}$, İsmail Topaloğlu², Hayati Mamur ${ }^{2}$ and Fatih Korkmaz ${ }^{2}$ \\ ${ }^{1}$ Faculty of Technology, Department of Electrical-Electronic Engineering, \\ Gazi University, Ankara, Turkey \\ ${ }^{2}$ Faculty of Engineering, Department of Electrical-Electronic Engineering, \\ Çankırı Karatekin University, Çankırı, Turkey \\ fkorkmaz@karatekin.edu.tr
}

\begin{abstract}
Field oriented control and direct torque control are the most popular methods in high performance industrial control applications for induction motors. Naturally, the strengths and weaknesses of each control method are available. Therefore, the selection of optimum control method is vitally important for many industrial applications. So, the advantages and the disadvantages of both control methods have to be well defined. In this paper, a new and different perspective has been presented regarding the comparison of the inverter switching behaviours on the FOC and the DTC drivers. For this purpose, the experimental studies have been carried out to compare the inverter switching frequencies and torque responses of induction motors in the FOC and the DTC systems. The dSPACE 1103 controller board has been programmed with Matlab/Simulink software. As expected, the experimental studies have showed that the FOC controlled motors have had a lessened torque ripple. On the other hand, the FOC controlled motor switching frequency has about $75 \%$ more than the DTC controlled.
\end{abstract}

\section{KEYWORDS}

Induction motor; machine vector control; motor drives; switching frequency

\section{INTRODUCTION}

Nowadays, induction motors have wide range use in many industrial applications with its simple and robust structure, low costs and reliable operation. Furthermore, the induction motors can be easily controlled due to development of new control methods in the last few decades. There are two well-known control methods in high performance control of induction motors: Field oriented control (FOC) and direct torque control (DTC).

FOC was first introduced by Blaschke in the 1970s. It was unrivalled in industrial induction motor drivers until DTC was introduced by Takahashi in the 1980s. Since that time, there have been continual discussions and studies in scientific and industrial arenas regarding which one is the best for the high performance control of induction motors [1-3].

The basic idea of vector control is the control of motor flux and torque separately as DC motors. For this aim, motor currents have converted two phase vector components using park or Clarke

David C. Wyld et al. (Eds) : SAI, CDKP, ICAITA, NeCoM, SEAS, CMCA, ASUC, Signal - 2014 pp. 13-19, 2014. (C) CS \& IT-CSCP 2014

DOI : $10.5121 /$ csit.2014.41102 
transformations. One of these is related with the component controlled flux vector, and the other one is related with the controlled torque vector. The main difference between these two methods is that the FOC controls by a rotor or stator field orientation, while the DTC controls by a stator field observation [4]. Depending on this difference, the structural differences in the two control strategies are that the FOC uses park transformation, more machine parameters, and current regulators, while the DTC uses Clarke transformation, fewer machine parameters, and any current regulators. Thus, comparative studies between the two methods show that the DTC is simplicity, a fast dynamic response, and is robust to parameter changes. Despite all these advantages, the DTC also has some handicaps: the most important of them being high torque and current ripples. Evidently all users have to take into account all these advantages and disadvantages when deciding on which method they will use on the motor drivers [5]. There are some comparative studies regarding comparison of the both methods, which address the motors speed and torque behaviours. Thanks to this research, it is now known that despite a high torque ripple, the DTC has a fast dynamic response [6-7].

In this study, we aimed to give a new and different perspective regarding the comparison of the FOC and the DTC drivers. We compared voltage source inverter switching frequencies on both the FOC and DTC systems. There is no doubt about the importance of switching frequency in motor driver systems because this directly affects switching losses and it means also affects indirectly the efficiency of the drivers. Experimental studies have been carried out to compare switching frequencies and the dSpace 1103 controller board has been programmed with Matlab/Simulink.

\section{BASICS OF FOC AND DTC}

FOC is the first vector control method developed for induction motors where it is mostly used to control the speed of the motor, not control of moment, due to its low level sensitivity [8].

In FOC, the parts of the motor have to be turned in a d-q reference frame, which then turns in a synchronous speed (park transformation). Thus, the position of the rotor flux needs to be well determined for the success of this transformation. Two basic approaches are used in determining the process of the rotor flux position. The first approach is to use flux sensors to determine the rotor flux position. The second approach is to measure the rotor position with an incremental encoder and calculate the angle between the axis of the rotor and the flux. The stator current $\mathrm{d}-\mathrm{q}$ components are calculated by using Eq. 1 and Eq. 2.

$$
\begin{aligned}
& i_{q s}^{*}=\frac{2}{3} \frac{2}{p}\left(\frac{T_{e}^{*}}{\lambda_{r}^{*}}\right)\left(\frac{L_{r}}{L_{m}}\right) \\
& i_{d s}^{*}=\frac{\lambda_{r}^{*}}{L_{m}}
\end{aligned}
$$

Where $i_{q s}^{*}$ and $i_{d s}^{*}$ are the stator current d-q components reference values, $\lambda_{r}^{*}$ is the rotor flux reference value, and $L_{m}$ is the mutual inductance, $L_{r}$ is rotor inductance and $\mathrm{p}$ is motor pole pairs value in these equations.

In Eq. 3., $\theta$ indicates the rotor angular position, and can be obtained from the integration of the sum of the rotor angular speed $\left(\omega_{r}\right)$ and the sleep angular speed $\left(\omega_{s l}\right)$ as given below. 
$\theta=\int\left(\omega_{r}+\omega_{s l}\right) d t$

and the sleep angular speed is obtained from Eq. 4.

$\omega_{s l}=\frac{L_{m} R_{r}}{L_{r} \lambda_{r}^{*}} i_{q s}^{*}$

The FOC control block diagram is created by using from Eq.1- Eq.4 and is shown in Fig. 1[9].

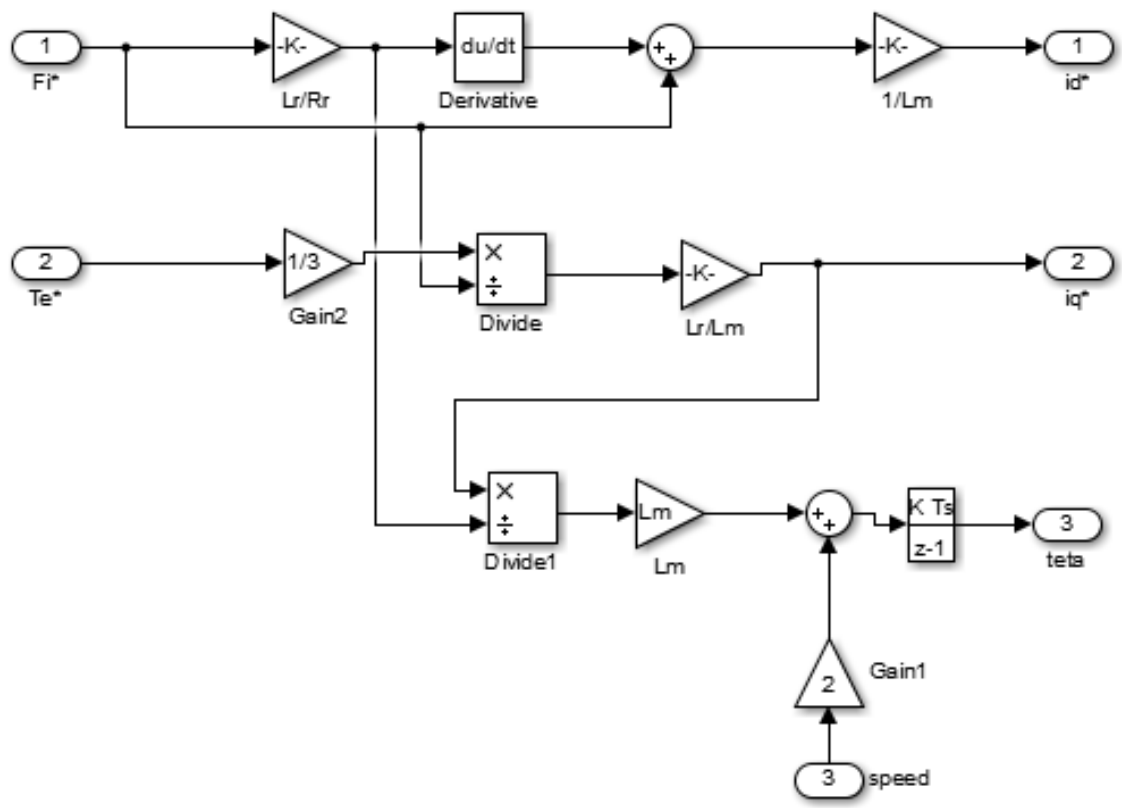

Fig. 1. Simulink block diagram of the FOC controller

In DTC, the stator flux and the torque are directly controlled by the system with using measured currents and voltages.

Instantaneous values of the flux and torque are calculated by using the transformation of the measured currents and the voltages of the motor. The stator flux is calculated as given in Eq.5-7 in a stationary reference frame [10].

$$
\begin{aligned}
& \lambda_{\alpha}=\int\left(V_{\alpha}-R_{s} i_{\alpha}\right) d t \\
& \lambda_{\beta}=\int\left(V_{\beta}-R_{s} i_{\beta}\right) d t \\
& \lambda=\sqrt{\lambda_{\alpha}^{2}+\lambda_{\beta}^{2}}
\end{aligned}
$$

Where, $\lambda_{\alpha}-\lambda_{\beta}$ are stator fluxes, $i_{\alpha}-i_{\beta}$ are stator currents, $V_{\alpha}-V_{\alpha}$ are stator voltages, $\alpha-\beta$ components and $R_{s}$ is the stator resistance. Motor torque can be calculated as given in Eq.8. 
$T_{e}=\frac{3}{2} p\left(\lambda_{\alpha} i_{\beta}-\lambda_{\beta} i_{\alpha}\right)$

Where, $\mathrm{p}$ is the motor pole pairs. The stator flux vector region is an important parameter for the DTC, and it can be calculated as given in Eq.9:

$\theta_{\lambda}=\tan ^{-1}\left(\frac{\lambda_{\beta}}{\lambda_{\alpha}}\right)$

The torque and flux errors, which are obtained by comparing the reference and observed values, are converted to control signals by hysteresis comparators. The switching table is used to determine the optimum switching inverter states, and it determines the states by using the hysteresis comparators outputs and the flux region data. The schematic view of the DTC system is given in Fig. 2 [10].

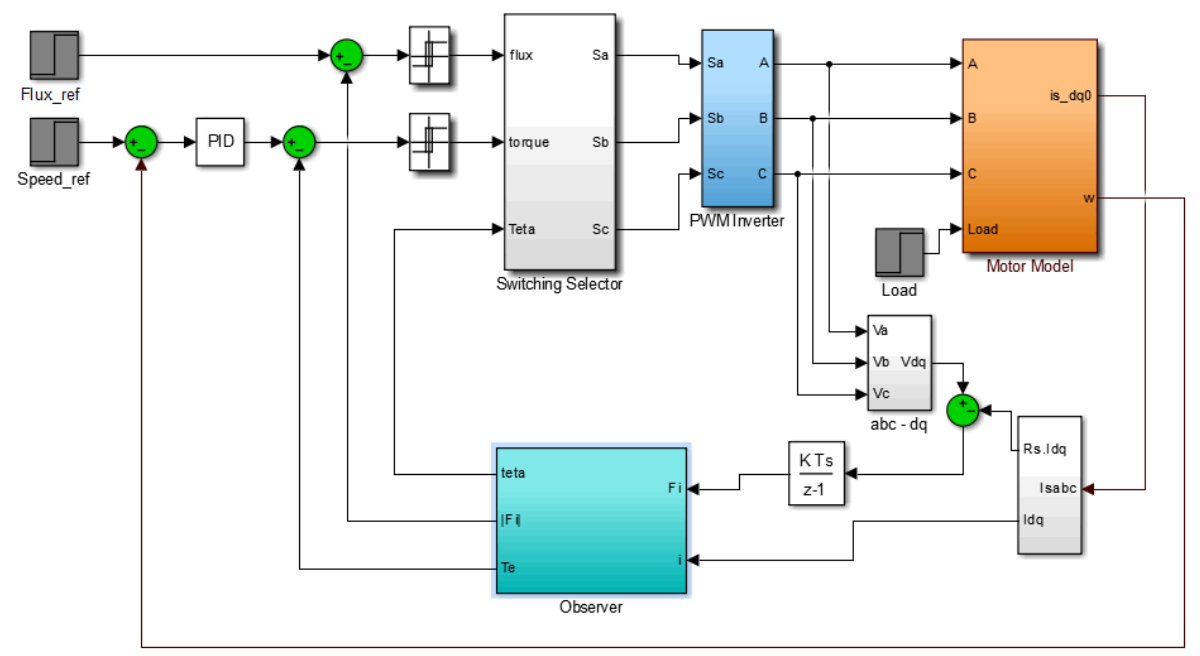

Fig. 2. Simulink block diagram of the conventional DTC

\section{EXPERIMENTAL STUDIES}

In order to compare the switching frequency between the DTC and the FOC systems, the experimental studies have been carried out by using the dSpace 1103 DSP (Digital Signal Processor) board. The board has been programmed in Matlab-Simulink Real-Time-Workshop environment for the tests.

A new frequency measurement block has created to compare the switching frequency on both systems. The inverter has had three arms and each arm frequency has been measured separately. The inverter switching frequency has been obtained by the addition of the arms switching frequencies, and then dividing the total by three. However, especially in the DTC, the switching frequency has a wide range, so the average switching frequency has been calculated with a different sampling time $(100 \mathrm{~ms})$ in the frequency measurement block to obtain healthy comparable results. 
The results of the experimental tests obtained in this study are for the induction motor of $4 \mathrm{~kW}$ and the parameters of the motor, and the experiments are as given below. The machine model is implemented for the DTC and the FOC schemes using the Matlab/Simulink. The DTC and the FOC systems were tested at under no load conditions. The parameters of the three-phase induction motor, in the SI units are given in Table 1.

Table 1. The parameters of the three-phase induction motor

\begin{tabular}{|l|l|}
\hline \multicolumn{2}{|l|}{ Motor parameters (SI) } \\
\hline Power $(\mathrm{kW})$ & 4 \\
\hline Voltage $(\mathrm{V})$ & 380 \\
\hline Current $(\mathrm{A})$ & 8.2 \\
\hline cos $\varphi$ & 0.85 \\
\hline Speed $(\mathrm{rpm})$ & 1425 \\
\hline Frequency $(\mathrm{Hz})$ & 50 \\
\hline Stator resistance $(\Omega)$ & 7.2 \\
\hline
\end{tabular}

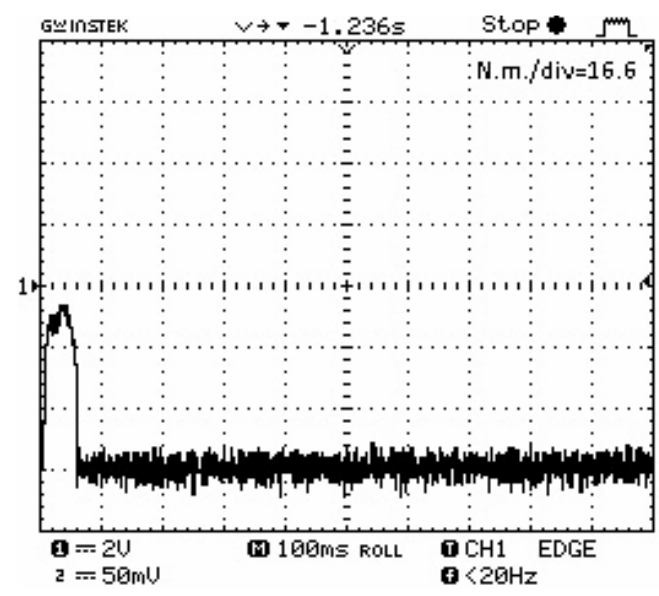

Fig. 3. Torque responses of unloaded DTC controlled motor

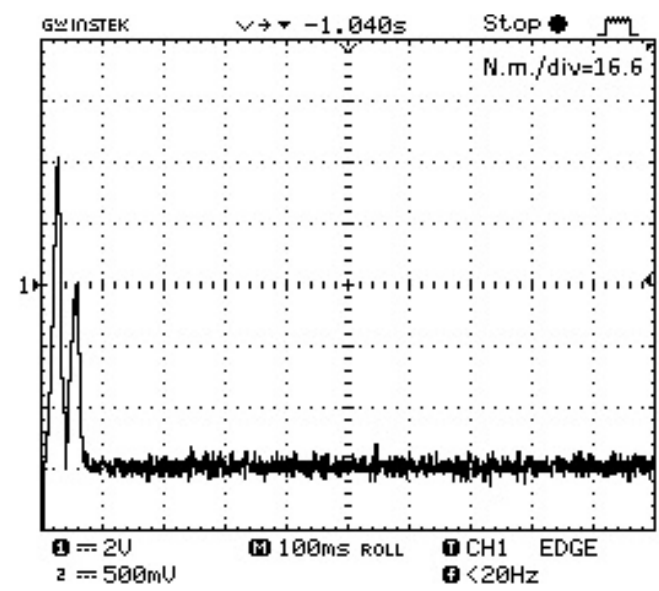

Fig. 4. Torque responses of unloaded FOC controlled motor 


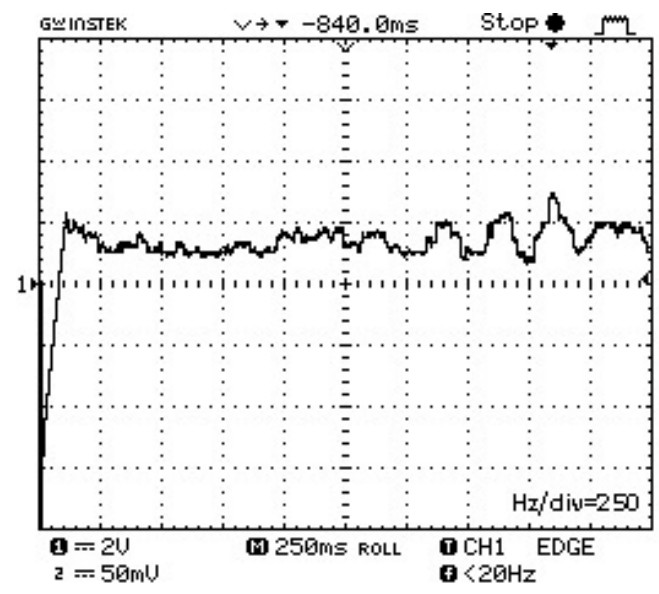

Fig. 5. Switching frequencies of unloaded DTC controlled motor

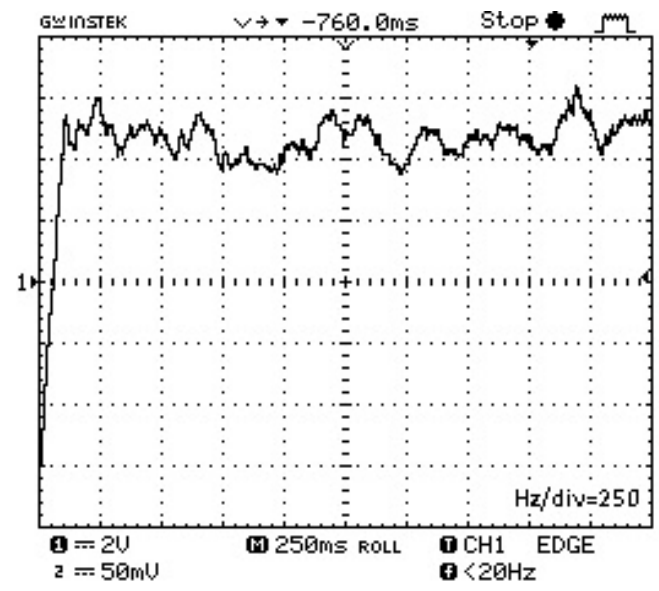

Fig. 6. Switching frequencies of unloaded FOC controlled motor

The motor reference speed is constant at $1500 \mathrm{rpm}$ over all the experimental tests. In the first part of the tests, the motor has been operated as unloaded. The moment and switching frequency data, which has been calculated within the Simulink blocks, have been obtained by using the digitalanalogue converters of the dSPACE 1103 controller board. The torque response curves of the motor for the both systems are given in Figure 3 and Figure 4 for unloaded working conditions. As expected, it can be clearly seen that the DTC has much torque ripples when compared the FOC.

Figure 5 and Figure 6 show change on the switching frequencies of the motor for both systems. The switching frequency of the DTC controlled motor is about $900 \mathrm{~Hz}$, while the FOC controlled motor is about $1600 \mathrm{~Hz}$. Therefore, it can be stated that the FOC controlled motor switching frequency has been $75 \%$ more than the DTC controlled one.

\section{CONCLUSIONS}

When designing an industrial application which includes electric motors, it is vitally important to choose motor drive method in order to operate the designed system efficiently. However, many times, it can be difficult to decide for any optimum control method for obtaining high performance regarding to induction motor drivers. Essentially, there are two options for the high 
performance induction motor drivers: FOC and DTC. This paper has aimed to give fair comparison between two vector control schemes for induction motor drives. For this aim, experimental tests have been realized to compare of the motor performances on different conditions.

After all experimental studies, it must be pointed out that the DTC method is preferable if the fast dynamic performance has primary importance whereas the FOC method might be a better option when high torque quality is demanded. In addition, a new frequency measurement block has been created to compare the switching frequency on both systems. The inverter switching frequencies have been investigated in the FOC and DTC systems to give a new criterion for the selection of optimum control strategy for induction motor high performance control. The experimental studies have been carried out to compare the switching frequencies in both methods under different load conditions. As a result, the FOC controlled motor switching frequency has been almost $75 \%$ more than the DTC controlled one under loaded and unloaded working conditions. The choosing of the DTC scheme will also provide high energy efficiency driver if the dynamic performance of the motor has primary importance.

\section{REFERENCES}

[1] V. Bleizgys, A. Baskys and T. Lipinskis, "Induction motor voltage amplitude control technique based on the motor efficiency observation", Electronics and Electrical Engineering - Kaunas: Technologija, 2011. - No. 3(109) - P. 89-92.

[2] Blaschke, F., "The Principle of Field Orientation Applied to The New Transvector Closed-Loop Control System for Rotating Field Machines", Siemens-Rev.,1972. - Vol. 39 - P. 217-220.

[3] Takahashi, I., Naguchi, T. A., "New Quick-Response and High-Efficiency Control Strategy of an Induction Motor", IEEE Transactions on Industry Application,1986. IA-22(5) -P. 820-827.

[4] Liu-Jun; Wang Wan-li, Wang Yang. "Research on FOC and DTC switching control of asynchronous motor based on parameter estimation", Automation and Logistics ICAL 2008. IEEE International Conference, 2008. - P. 1754-1758.

[5] Farasat, M.; Rostami, N.; Feyzi, M. R., "Speed sensorless hybrid field oriented and direct torque control of induction motor drive for wide speed range applications", Power Electronic \& Drive Systems \& Technologies Conference (PEDSTC), 2010. - P. 243-248.

[6] Casadei, D.; Profumo, F.; Serra, G.; Tani, A., "FOC and DTC: two viable schemes for induction motors torque control", Power Electronics, IEEE Transactions, 2002. -Vol.17- No.5 - P. 779-787.

[7] Wolbank, T.A.; Moucka, A.; Machl, J.L., "A comparative study of field-oriented and direct-torque control of induction motors reference to shaft-sensorless control at low and zero-speed", Intelligent Control, 2002. Proceedings of the 2002 IEEE International Symposium. - P. 391-396.

[8] T. V. Mumcu, I. Aliskan, K. Gulez, G. Tuna, "Reducing Moment and Current Fluctuations of Induction Motor System of Electrical Vehicles by using Adaptive Field Oriented Control", Electronics and Electrical Engineering - Kaunas: Technologija, 2013. - Vol. 19 - No.2 - P. 21-24.

[9] Krishnan, R. Electric Motor Drives // Prentice Hall, P.450 2001.

[10] Fatih Korkmaz, M.Faruk Çakır, İsmail Topaloğlu, Rıza Gürbüz, "Artificial Neural Network Based DTC Driver for PMSM", International Journal of Instrumentation and Control Systems (IJICS) Vol.3, No.1,pp. 1-7 Jan. 2013 